\title{
LÁ ONDE, CARA PÁLIDA? \\ PENSANDO AS GLÓRIAS E OS LIMITES DO CAMPO ETNOGRÁFICO ${ }^{1}$
}

\author{
CLAUDia FonseCA ${ }^{2}$
}

\begin{abstract}
RESUMO
$\mathrm{Na}$ época dos pais fundadores da antropologia, a distância que separava o pesquisador do seu "campo" parecia óbvia; hoje, a situação é radicalmente diferente. Navegando entre elementos metodológicos e éticos dessa distância, proponho nesse artigo tecer uma reflexão sobre meu posicionamento em relação a certo "campo" um território originalmente criado para ser hospital-colônia de portadores de hanseníase (lepra) no nordeste brasileiro. Atenta às preocupações de meus interlocutores atuais e a suas narrativas sobre uma história secular, tento localizar as diferentes mediações que constituem (ou não) um sentido de comunidade. Minha ênfase nas mediações materiais (tecnologias médicas, lesão corporal, leis de indenização) constrói a "experiência de doença" não de um sujeito unitário, mas de atores envolvidos numa rede sócio-técnica que desenha os limites cambiantes de determinado coletivo. É a partir desse jogo de marcadores de "dentro" e "fora", realçados em momentos históricos distintos, através de medidores particulares, que procuro construir meu próprio posicionamento como mais um elemento na ebulição de memórias, identidades e compromissos.
\end{abstract}

\section{PaLAVRAS ChaVe \\ Etnografia responsiva; Método etnográfico; Ética de pesquisa; Rede sócio-técnica; Hanseníase}

\author{
"BEING THERE" WHERE? \\ REFLECTIONS ON THE GLORIES AND LIMITS OF THE ANTHROPOLOGICAL FIELD
}

\begin{abstract}
At the time of anthropology's founding fathers, the distance separating the researcher from his field appeared to be obvious; today, the situation is radically different. Navigating between methodological and ethical elements of this distance, I propose in the article to weave a reflection about how I am situated in relation to my latest "field" -- a territory originally created as hospital-colony for patients of Hansen's disease (leprosy) in Northeast Brazil. In dialogue with my interlocutors' concerns and their narratives revolving around their century-old story, I try to locate the different material mediations that constitute (or not) a sense of community. My emphasis on material mediations (medical technologies, corporal lesion, laws of reparation) construct the experience of malady not of a unitary subject, mas of actors involved in a socio-technical network that sketches the changing limits of a certain collective. It is through this interplay of elements attempting to mark a "within" and "without" -- terms that fluctuate according to different historical moments and particular instruments of measurement --, that I seek to construct my own location, in this cauldron of memories, identities and engagements.
\end{abstract}

\footnotetext{
${ }^{1}$ Esse artigo foi redigido para dialogar com os autores da coletânea, "O espírito da etnografia" organizada por Jurema Brites e Flavia Motta, a ser publicada até o início de 2018 pela Editora da UNISC, Santa Cruz do Sul.

${ }^{2}$ Professora no Programa de Pós-Graduação em Antropologia Social da Universidade Federal do Rio Grande do Sul (Brasil) e no Doutorado em Antropologia da Universidad Nacional de San Martin (Argentina).
} 


\title{
KEY WORDS \\ Responsive ethnography; Ethnographic methods; Ethics in research; Socio-technical networks; Hansen's disease
}

\author{
"LÀ-BAS \#, OU்? GLOIRES ET LIMITES DU TERRAIN DE RECHERCHE ETHNOGRAPHIQUE
}

\begin{abstract}
RÉSUMÉ
À l'époque des pères fondateurs de l'anthropologie, la distance qui séparait le chercheur et son "terrain" semblait aller de soi; aujourd'hui la situation est radicalement différente. En parcourant des éléments méthodologiques et éthiques de cette distance, je propose dans cet article de tisser une réflexion sur ma prise de position par rapport à un "terrain": un lieu originalement créé pour être un hôpital-colonie de personnes porteurs de la Maladie de Hansen (lèpre) dans la région nord-est du Brésil. Attentive aux questions de mes interlocuteurs et à ses récits sur une histoire séculaire, j'essaye de définir des éléments médiateurs qui constituent (ou pas) un sens de communauté. En soulignant les médiations matérielles (technologies médicales, blessures corporelles, lois d'indemnisation), je tâche de construire « l'expérience de la maladie » non d'un sujet individuel, mais d'acteurs dans un réseau sociotechnique qui désigne les limites changeants d'un certain collectif. C'est à partir de ce jeu de marqueurs de "dedans " et " dehors ", mis en relief à certains moments historiques par des médiateurs particuliers que je cherche à construire ma prise de position comme un parmi d'autres éléments dans le chaudron de mémoires, identités et engagements.
\end{abstract}

\section{MOST-CLÉS}

Ethnographie responsive; méthodes ethnographiques; éthique de recherche; réseaux sociotechniques; Maladie de Hansen

\section{¿ALLA DÓNDE, CARA PÁLIDA? PENSANDO LAS GLORIAS Y LOS LÍMITES DEL CAMPO ETNOGRÁFICO}

\section{RESUMEN}

En la época de los padres fundadores de la antropología, la distancia que separaba al investigador de su "campo" parecía obvia; Hoy, la situación es radicalmente diferente. Al discurrir sobre los elementos metodológicos y éticos de esa distancia, propongo en ese artículo tejer una reflexión sobre mi posicionamiento en relación a cierto "campo" - un territorio originalmente creado para ser hospital-colonia de portadores de hanseniasis (lepra) en el nordeste brasileño. Atenta a las preocupaciones de mis interlocutores actuales y sus narrativas sobre una historia secular, intento localizar las diferentes mediaciones que constituyen (o no) un sentido de comunidad. Mi énfasis en las mediaciones materiales (tecnologías médicas, lesión corporal, leyes de indemnización) construye la "experiencia de enfermedad" no de un sujeto unitario, sino de actores involucrados en una red socio-técnica que dibuja los límites cambiantes de determinado colectivo. Es a partir de ese juego de marcadores de "dentro" y "fuera", realzados en momentos históricos distintos, a través de medidores particulares, que busco construir mi propio posicionamiento como un elemento a más en la caldera de memorias, identidades y compromisos.

PALABRAS CLAVE

Etnografía responsiva; Método etnográfico; Ética de investigación; Red socio-técnica; Lepra 


\section{INTRODUÇÃO}

Li esses dias um "velho" texto que exprime algo que muitos de nós sentimos nesses últimos tempos sobre etnografia. Os autores, Gupta e Ferguson (1997), apontam para o paradoxo de as reviravoltas radicais na teoria antropológica não serem acompanhadas por uma reformulação igualmente radical de discussões metodológicas. Por um lado, rejeita-se a ideia de comunidades delimitadas e culturas homogêneas - agora a ênfase está em fronteiras porosas e pessoas, objetos, e ideias em deslocamento. Por outro lado, os antropólogos querendo reafirmar sua identidade disciplinar - insistem mais do que nunca na "pesquisa de campo" radicada num determinado "local":

"O que fazer com uma disciplina que rejeita ruidosamente "o local", ao mesmo tempo em que insiste com cada vez mais firmeza num método que toma o local como um dado óbvio?" (GUPTA; FERGUSON, 1997, p. 4)

De certa forma, esses autores estão colocando em questão o "eu estive lá" realçado por Geertz (1989 [1973]) como pilar do trabalho etnográfico no início dos anos 1970. Sugerem que as clássicas narrativas de "como entrei" e "como vim embora" do campo reforçam a ideia de distância entre o mundo do etnógrafo e o dos etnografados. O olhar "orientalista" estaria inscrito nas próprias convenções do contar da aventura.

Contudo, ao mesmo tempo que insistem em descentrar a noção de campo enquanto elemento sine-qua-non do trabalho etnográfico, Gupta e Ferguson não estão propondo descartar as lições dos métodos clássicos. Consideram que o "deslocamento" tão recomendado a pesquisadores iniciantes não implica necessariamente num campo fetichizado ou na transformação dos interlocutores em Outros exóticos. É possível, sem cair nessas armadilhas, aproveitar as vantagens da "viagem" - a relativização do conhecimento hegemônico ocidental, a escuta e valorização do que dizem os sujeitos de estudo, a consciência do posicionamento de perspectivas transmitidas a partir de situações socialmente e politicamente diferentes. Lembrando que as tradições se fazem de frente para trás, admitem que o "campo" continua sendo um componente central da tradição antropológica - mas, agora, como parte de uma tradição reinventada conforme as circunstâncias contemporâneas.

Aproveitando os insights de Donna Haraway (1995) sobre o "conhecimento situado", os autores propõem uma renovação de vocabulário que deslocaria a ênfase na pesquisa etnográfica de "localidade" para "sítio" 4 e, em particular, para o trabalho investido tanto pelo pesquisador quanto pelos seus interlocutores na construção desse "sítio". Tal abordagem,

\footnotetext{
${ }^{3}$ Essa, tal como as demais traduções do inglês nesse artigo, foi realizada pela autora.

${ }^{4}$ No original, em inglês, o deslocamento é de locality para location. Em vez de "locação", nos parece que a tradução mais adequada desse último termo em português seria "sítio" ou "posicionamento".
} 
além de estabelecer conexões epistemológicas e políticas entre conhecimentos produzidos a partir de diferentes sítios, permitiria explorar possíveis alianças e, eventualmente, um propósito comum entre eles.

É nesse deslocamento sutil, do metodológico ao ético, que proponho tecer uma reflexão sobre meu posicionamento em relação a certo "campo" - um território originalmente criado para ser hospital-colônia de portadores de hanseníase (lepra) no nordeste brasileiro. Durante boa parte do século passado, as pessoas sofrendo de hanseníase eram segregadas contra sua vontade nessas pequenas cidades-hospitalares. Este fato já deu origem a uma série de análises inspiradas nas perspectivas de Foucault(2011) tecnologias disciplinares de governo, e Goffman $(1963 ; 2007)$ - estigma, instituições totais 5 .

Nesse artigo, entretanto, meu interesse é outro. Atenta às preocupações de meus interlocutores atuais e a suas narrativas sobre uma história secular, tento localizar as diferentes mediações que constroem (ou não) um sentido de comunidade. Minha ênfase nas mediações materiais (tecnologias médicas, lesão corporal, leis de indenização) constrói a "experiência de doença" não de um sujeito unitário, mas de atores envolvidos numa rede sócio-técnica que desenha os limites cambiantes de determinado coletivo (LATOUR, 2005). É a partir desse jogo de marcadores de "dentro" e "fora", realçados em momentos históricos distintos, através de medidores particulares, que procuro construir meu próprio posicionamento como mais um elemento na ebulição de memórias, identidades e compromissos.

\section{DENTRO E FORA}

As provocações colocadas por Gupta e Ferguson (1997) vieram em boa hora. Não fazia uma semana que eu tinha voltado do meu último "campo" ${ }^{6}$ quando li o texto. O campo no meu caso ainda se apresentava nos termos clássicos: era uma ex-colônia de hanseníase, localizada do outro lado do rio da cidade de São Luís de Maranhão ${ }^{7}$. Não podia haver uma delimitação territorial mais clara. O lugar tinha sido criado em função de seu isolamento

\footnotetext{
${ }^{5}$ Ver Curi (2010), Mendonça (2009), Serres (2009) como algumas das diversas teses e dissertações escritas sobre as colônias, sublinhando a relevância para suas análises de Goffman(2007) e Foucault (2011).

${ }^{6}$ Apesar das críticas, sigo empregando o termo clássico por facilitar a leitura.

${ }^{7}$ Nessa minha segunda viagem para a Colônia de Bonfim, fiquei uma semana (início de junho 2016), morando no centro comunitário no seio da antiga colônia, junto com a pesquisadora Glaucia Maricato que me acompanhava em todos os momentos da pesquisa e com quem desenvolvi boa parte das reflexões expostas nesse artigo. Também gostaria de agradecer a Ana Maria dos Santos Martins Pinho e Flavio Serafim Lisboa, ambos ligados ao Memorial da antiga colônia, que contribuíram muito para o desenrolar dessa pesquisa.
} 
geográfico. E sucessivas leis tinham reforçado essa delimitação, ora suprimindo, ora ampliando direitos de pessoas justamente em função delas estarem dentro ou fora da colônia. A mais recente datava de 2007 - a lei federal 11.520 que concedia uma pensão vitalícia a pessoas que tinham sido "compulsoriamente internadas" nas colônias. Para serem contemplados, os candidatos à reparação deviam comprovar, com documentos ou, eventualmente, testemunhos, que tinham sido internadas em uma das quarenta e poucas colônias brasileiras até 1986 (MARICATO, 2015).

Não era um problema para mim reconhecer o quanto os limites desse espaço tinham sido criados e fortalecidos através da intervenção "de fora" - pela atuação estatal na forma de políticas higienistas, pelo movimento social $\left(\mathrm{MORHAN}^{8}\right)$ que exigia reparação pela violação dos direitos fundamentais dos internos e pelos jornalistas e pesquisadores que traduziam a história desses locais para um público ávido de detalhes 9 .

Mas as mesmas forças que firmavam os limites territoriais do meu campo também forneciam sementes para subverter qualquer demarcação nítida. Artur Custódio, diretor do MORHAN quando iniciei essa pesquisa, me chamou atenção para uma certa limitação da maioria das pesquisas que não se desgrudavam do espaço territorial das colônias. Será que não existia um grande contingente de doentes vivendo em isolamento ou com seus familiares nas aldeias interioranas? Como seriam as condições e tratamento dessas pessoas não enquadradas na colônia? Não é por acaso que, em 2016, MORHAN, em parceria com o governador de Acre, Tião Viana (um infectologista que há tempo milita em prol dos pacientes de hanseníase), estava celebrando os avanços de um projeto estadual que estenderia o direito a reparação a pessoas atingidas de hanseníase que tinham sido submetidas à prática de "isolamento compulsório de forma domiciliar"10.

Essa flexibilização conceitual dos lugares de internamento/isolamento compulsório que despontava no discurso político - meu "campo" me convencia - era devida à influência dos próprios "atingidos" que nunca limitaram suas práticas (ou suas lembranças) às categorias formais dos mapas bidimensionais. Mas isso não quer dizer que não exista uma identidade solidária entre as pessoas que passaram por "lá" - a Colônia do Bonfim do Maranhão.

${ }^{8}$ Movimento de Reintegração das Pessoas Atingidas pela Hanseníase (ver http://www.morhan.org.br/)

${ }^{9}$ Ver, por exemplo, os diversos artigos de História, Ciências, Saúde. Manguinhos, 10 (suplemento1), 2003. Entre as muitas teses e dissertações em Ciências Sociais, Antropologia, Comunicação e História sobre as Colônias de hanseníase, citamos apenas duas sobre especificamente a Colônia de Bonfim: Câmera (2009) e Nascimento (2010).

10 Disponível em: http://www.agencia.ac.gov.br/governo-e-morhan-tratam-da-extensao-dobeneficio-para-hansenianos/. Acesso em: fevereiro de 2017). 


\section{FRONTEIRAS ONTEM E HOJE}

Nas suas conversas comigo, os residentes mais antigos demonstravam uma forte sensação de comunidade materializada através dos lugares e edifícios que compõem a antiga Colônia do Bonfim. Hoje, os limites dessa comunidade deixaram de ser traçados por muros. O antigo portão de pedra que, nos primeiros tempos da colônia, demarcava a entrada na zona dos "doentes", foi removido da estrada e transportado para a margem lateral do hospital, servindo hoje apenas para reviver a memória dos anos de confinamento. Antes mesmo de chegar ao portão, passamos pelo cemitério do local onde, entre muitas covas sem identificação, localizamos placas e monumentos designando os restos mortais de alguns personagens importantes da história da Colônia - certo padre, Dona Domingas (líder comunitária), etc. Mas, começam já aqui os comentários da parte de nossos guias de que hoje em dia estão trazendo "pessoas de fora" - isto é, que nunca tiveram nada a ver com a hanseníase - para serem enterradas nesse chão.

$\mathrm{Na}$ frente do Hospital Aquiles Lisboa encontra-se o antigo cinema da colônia que funciona atualmente como auditório para conferências e reuniões profissionais. Logo depois, adentramos uma zona de prédios intercalados da atual e antiga administração. Cem metros além de uma ala de internamento hospitalar com uma dúzia de pacientes (a maioria do interior) em tratamento, ficam as ruínas da antiga cantina e a pracinha do alto-falante já há décadas em desuso. No coração desse conjunto arquitetônico, encontramos a principal rua residencial, de uns 300 metros, que vai da capela, inaugurada nos primeiros dias da Colônia e já em estado avançado de delapidação, até os escombros da antiga escola primária. No meio dessa estrada de paralelepípedo, passa-se pela praça gramada da atual igreja. As pequenas casas ladeando a avenida que, em tempos idos, abrigavam casais, estão com necessidade urgente de reforma. Contudo, mesmo assim, são objeto de cobiça, reservadas para pessoas escolhidas pelo Conselho Gestor do Hospital (composto de ex-internos assim como representantes do atual hospital).

Do outro lado desse conjunto, uns 50 metros além da antiga cantina, já inicia o que ficou na memória como a "zona dos sadios" - onde moravam os funcionários da Colônia. É uma zona privilegiada da área peninsular, desembocando no cais da lancha que partia cotidianamente para a capital. É nessa zona que morava o diretor da Colônia, numa mansão à beira da praia, e também é aqui que morava a multidão de empregados junto com suas famílias, cujos filhos frequentavam uma escola local exclusivamente deles. Diz-se que, "antigamente", a barreira entre o território dos "sadios" e o "dos doentes" era praticamente intransponível. Eventualmente, formavam-se amizades entre indivíduos das duas categorias, mas as circunstâncias impediam qualquer convivência mais íntima. Com o fim da segregação compulsória e à medida que os filhos de pacientes e funcionários foram crescendo, houve 
intercasamento de forma que, hoje, é possível encontrar alguns ex-internos ou filhos de exinternos morando na zona "dos sadios", mas são poucos. Com o tempo, graças especialmente às políticas sociais que garantem uma renda fixa a antigos asilados, as antigas hierarquias de poder - que colocavam os funcionários/"cuidadores" nitidamente acima das pessoas cuidadas - se corroeram e, em certos casos, foram invertidas.

Em todo caso, as duas categorias - funcionários e "doentes" - outrora tão distintas, reconhecem atualmente uma afinidade mais do que territorial, no compartilhamento de uma experiência histórica da colônia. Agora, os "de fora" são os recém-chegados - os que vieram com a "invasão" de uns anos atrás. Gradativamente, a construção de uma estrada e, em particular, uma ponte ligando os dois bancos do rio Bacanga, tornaram toda essa área um subúrbio de São Luís (capital do estado). Houve um intenso povoamento dos bairros contíguos ao Hospital - Vila Nova e Anjo da Guarda-, com uma parte dos novos residentes transbordando para dentro das terras que tinham sido da Colônia. Hoje, existem dezenas de "carrinhos" 11 fazendo a ida e volta entre esses bairros e o Hospital, e entre o Hospital e os cais da lancha, de forma que o "comércio" não fica longe. É assim que se explica o aparecimento de novos moradores nas barracas abandonadas frente às ruínas da primeira capela onde, em tempos idos, moravam os solteiros da Colônia. É assim que se explica também uma porção de novos moradores na antiga zona dos funcionários. Esses recémchegados são vizinhos. Portanto, não se fala de "invasores". Mas, sempre quando eu perguntava aos meus interlocutores sobre algum indivíduo ou a família desses, егa logo lembrada da irrelevância desses sujeitos para minha pesquisa: "Não são da Colônia. São da invasão".

O sentido de comunidade, contudo, não se restringe ao território geográfico. Ao longo das conversas com os ex-internos e seus muitos familiares, fui descobrindo outros conectores fundamentais que moldavam o "dentro" e "fora" da colônia - essa vez delimitando o universo de "doentes" e reforçando a causa comum entre eles: bacilos, feridas corporais e leis. Cada conector implicava mediações distintas para traçar os limites de determinado grupo, provocando o remanejamento de experiências e identidades.

\section{NEGATIVADO E/OU MELHORADO: OUTROS LIMITES TERRITORIAIS}

Nas minhas visitas a outras colônias, e em minhas leituras, eu já tinha aprendido a importância de um paciente "negativar" no exame da baciloscopia. Na memória de meus

\footnotetext{
${ }^{11}$ Trata-se de carros particulares, sem identificação alguma, cujos motoristas, por uma tarifa fixa de $\mathrm{R} \$ 3,00$ por passageiro, completam o sistema de transporte centrado no ônibus urbano. Enchem de passageiros a medida que avançam no itinerário e levam para endereços particulares desde que estejam dentro dos bairros em questão.
} 
interlocutores, existe - pelo menos desde os anos 60 - "aquele teste chato" aplicado a pessoas suspeitas de ter contraído hanseníase. É chato porque exige extrair uma amostra dos mucos, geralmente do nariz ou da orelha, para testar pela presença do bacilo patogênico (um senhor particularmente expressivo me jurava que naquela época usavam qualquer coisa para fincar no nariz ou para apertar a orelha - até alicate). O primeiro resultado positivo marcava um momento dramático para o paciente, nem tanto pela tomada de consciência da gravidade de sua doença (a maioria de pessoas já vivia há tempo com o sofrimento físico, mesmo antes da doença ser nomeada), mas pela reação dos outros. Não só a pessoa assim diagnosticada era, com frequência, violentamente expulsa de sua casa e vizinhança originais, mas perdia - por lei - a liberdade fundamental de ir e vir ${ }^{11}$.

Era um resultado positivo da baciloscopia que decretava o confinamento do paciente na Colônia e era um teste negativo que dava esperança de poder sair. Já ouvi muitas vezes dos residentes mais antigos que, para visitar um filho no educandário, tinha que primeiro "dar negativo" no teste. E para receber alta, com permissão de ir embora da colônia, era só depois de ser testado em doze meses consecutivos, sempre com resultado negativo. Assim, na memória das pessoas e, de fato, nas orientações administrativas de muitas colônias, atribuía-se uma enorme importância ao fato de "negativar" no exame. Parecia significar a cura, ou pelo menos a progressão na direção da cura e, com ela, o direito de sair definitivamente da Colônia. A ficha mostrando o resultado de exame era um documento capaz de mudar o status do interno e, em princípio, de the dar acesso livre ao "mundo lá fora".

A ironia é que, pelo menos hoje, o teste não é considerado fidedigno. Muitas pessoas, apesar de receber um claro diagnóstico de hanseníase por métodos clínicos, têm resultado negativo na baciloscopia (Dados do setor ambulatorial do Hospital Aquiles Lisboa em São Luís mostram que menos da metade dos casos novos dão resultado positivo no teste). E pelo menos um ex-interno me jura que foi internado a primeira vez (no início da década de 1960) por causa de um resultado positivo errado. Nada impede, contudo, que esse exame laboratorial - que, com o apoio de alguns técnicos e microscópios, pretende mostrar a invasão do corpo por um inimigo invisível, o bacilo da hanseníase - tenha sido e continue sendo um demarcador de fronteiras sociais, constituindo o lugar de onde a pessoa deve se ver e planejar sua vida.

Entretanto, quando cheguei à Colônia do Bonfim, me dei conta de que esse "lugar" tinha muitos outros condicionantes. Um destes - talvez o mais importante - não apostava em micro-organismos invisíveis, não dependia da parafernália de um laboratório médico. Estava arraigado no que era mais aparente da pessoa: seu corpo físico. E o vocabulário usado para designar o divisor de águas não era mais "negativado" e, sim, "melhorado". Ironicamente, este termo tinha quase nada a ver com uma progressão positiva da doença. Designava, pura 
e simplesmente, quem não sofrera os efeitos mutiladores da doença. Usava-se o termo, por exemplo, para falar dos meninos que tinham direito de seguir seus estudos, tomando a lancha diariamente ou vivendo numa pequena casa "arranjada" pelas freiras, para frequentar um colégio no centro da cidade. Conforme uma antiga moradora:

As crianças melhoradas, que não tinham nada, que ninguém sabia, podiam estudar lá na cidade. (...) Isso era para aqueles rapazes que não tinham nada, mas ninguém podia saber.

Na memória dos narradores, só se a doença fosse completamente invisibilizada - aos olhos tanto dos colegas de escola quanto dos vizinhos da casa alugada - é que os jovens em questão podiam realizar seu programa de estudos ${ }^{12}$. As outras crianças, aquelas cujos corpos anunciavam ao mundo que eram portadoras de hanseníase, não podiam sair da Colônia. Por inteligentes que fossem, seus estudos seriam fatalmente limitados aos dois ou três anos (dependendo da época) de ensino oferecido por um professor, ele mesmo "doente", na escolinha da Colônia.

Outra senhora, já com 70 anos, fala da dificuldade que teve, chegando ainda criança do interior, para ser admitida na Colônia apesar do diagnóstico de hanseníase:

Falaram que era crime me internar. Foi a maior luta. É porque eu era bem melhorada. Não tinha quase nada, só umas manchas.

Trata-se de uma mulher em que "a doença não evoluiu", mas que ficou morando 18 anos na Colônia, com funções específicas: "Naquela época, os melhorados tinham que cuidar dos outros". Casou com "doente", vendo seus quatro bebês, nascidos na Colônia, levados embora para o orfanato. Ela, diferentemente de muitos outros pais, conseguiu manter contato com seus filhos: "Eu tinha visitado eles sempre. Podia visitar porque, sendo melhorada, eu tinha declaração do diretor, para poder visitar. "

De fato, dependendo da modalidade da doença, a resistência do corpo individual e a resposta a tratamentos disponíveis, algumas pessoas diagnosticadas com hanseníase nunca tiveram mais do que algumas manchas ou outros sintomas invisíveis à observação superficial. É possível que seus exames também dessem negativo mas, ao que parece, o critério principal para entrar na turma dos "melhorados" e ter maior liberdade para ir e vir tinha pouco a ver com a contagem de bacilos nos fluidos corporais, ou, por extensão, com o potencial contagiante do paciente. Tinha, sim, a ver com os sinais visíveis do corpo - bolhas na pele, feridas abertas, mãos e pés atrofiados ou rosto deformado - capazes de espantar os interlocutores.

12 O estigma que carregava a doença, se estendendo a filhos e parentes dos portadores de hanseníase e que podia ser acionado pelo simples fato de morar dentro ou perto da colônia, será aprofundado em outro lugar. Basta aqui destacar como, na luta política por medidas reparatórias, o MORHAN tem procurado contar "a história que o Brasil quer esquecer", revertendo o que tinha sido, no passado, um "segredo vergonhoso" em violação de direitos humanos. 
O "internamento compulsório" representa uma época quando a liberdade de ir e vir de todos os pacientes era rigorosamente controlada pelas autoridades da Colônia. Mas havia outro tipo de controle suplementar que extrapolava o tempo e o espaço da Colônia: o olhar dos "sadios" que reagiam às mutilações visíveis provocadas pela doença. Por exemplo, em muitos casos, as autoridades do educandário não admitiam a visita de pais, mesmo negativados, se estes exibiam feridas ou outras consequências debilitantes da doença. $E$, garantem meus interlocutores, muitos pais neste estado não iam querer visitar, pois "não queriam assustar as crianças".

É significativo o comentário de Dona Laurinda ${ }^{13}$, senhora idosa, residente até hoje da Colônia do Bonfim que, sentada no seu alpendre, tagarelava comigo certo fim de tarde. Tinha encontrado ela, como de costume, conversando com duas outras mulheres bem mais jovens que faziam parte da convivência vicinal. Uma delas era "filha" de Dona Laurinda, isto é, uma ex-interna que, tendo chegado ainda criança na Colônia, tinha sido acolhida por essa senhora. A outra, apesar de nunca ter contraído a doença, tinha visto sua própria mãe internada na Colônia trinta anos atrás. Eu estava tentando definir com precisão o ano em que a política de internamento tinha mudado para permitir a "abertura" da Colônia, com o livre ire-vir dos residentes. Me referindo ao internamento da mãe doente, indaguei, "Mas naquela época, já dava para os pacientes saírem para visitar suas famílias"? A resposta que veio da velha senhora, ela mesma com marcas visíveis da doença no rosto e nas mãos, foi logo respaldada pelas duas outras: "Mas, era impossível. A gente não podia sair". Para elas, o confinamento era tão óbvio que dispensava qualquer qualificação quanto a datas, leis ou políticas particulares do diretor.

Logo lembrei das mil e uma histórias que tinha ouvido de ex-internos sobre suas vidas, geralmente no interior, antes de qualquer internamento. Existiam aqueles que sublinhavam a solidariedade dos familiares e a ajuda dos vizinhos, mas tinha outros que falavam de formas violentas de rejeição. Dependendo dos estragos da doença, a pessoa nem conseguia transporte para chegar ao hospital mais próximo (a história clássica é como a pessoa tinha que se esconder num caixote fechado, se tornando invisível, para poder ser transportada em caminhão). Seu Vitor - um senhor idoso com mãos comprometidas pela doença - tinha me falado dos enfrentamentos com desconhecidos quando, ainda jovem, ele ousava entrar num bar ou se aventurava num lugar público fora da Colônia. As pessoas o ofendiam, o acusavam de querer "espalhar essa praga", o ameaçavam de morte. Parece que só quando fez amizade com certo administrador do hospital e passou a acompanhá-lo em passeios fora da Colônia ele começou a ter certa "liberdade de ir-e-vir". Mas, admite que, até hoje, não aceita facilmente circular fora das redondezas da antiga Colônia sem um amigo por

\footnotetext{
${ }^{13}$ Este, como os nomes subsequentes usados para denominar um interlocutor, são pseudônimos.
} 
perto. Mais do que as inconveniências de sua deficiência física, ele teme o olhar dos outros. Assim, quando Dona Laurinda afirma categoricamente que "não podia sair", entendemos que está falando de uma realidade que não dependia de cercas de arame, portões de pedra ou políticas sanitárias.

É interessante que não se use "positivar" (рara falar de um resultado positivo da baciloscopia), e raramente se fale de alguém "piorado"14. "Negativar" e "melhorado" são termos carregados de conotações esperançosas, cunhados para falar de uma ampliação dos territórios - tanto geográficos quanto sociais - por onde os afetados de hanseníase têm direito de andar. Por outro lado, esses termos também são capazes de afetar identidades e criar fronteiras internas à categoria de "doente", separando os que desfrutavam de maior liberdade do que outros. Um critério se remetia a elementos invisíveis no corpo revelados pelo instrumental de especialistas, outro dizia respeito ao que havia de mais visível no corpo -feridas na pele e outros selos estigmatizantes. Mas ainda existia um terceiro critério, propriamente administrativo, para determinar quem pertencia à comunidade: a questão da "alta" hospitalar.

\section{RECEBENDO ALTA: 0 IMPULSO INSTITUCIONAL}

Ao pensar o "dentro" e "fora" da colônia, existe, além de "negativado" e "melhorado", uma terceira categoria - em determinados aspectos, o mais decisivo - para pensar a relação das pessoas com o espaço geográfico da Colônia: a "alta", categoria que designa quem foi considerado curado e liberado do tratamento hospitalar.

Maranhão foi um dos primeiros estados a votar um incentivo financeiro para que as pessoas negativadas fossem embora da colônia hospitalar. Até então, não existia política para facilitar a vida dos egressos. Um interlocutor, falando de sua irmã que recebeu alta em 1956, me pergunta: "Sabe qual era [a política] naquela época? A direção dava 5 cruzeiros e um saquinho de remédios para a gente se virar lá fora". E acrescenta, com indignação, detalhes sobre outros casos de pessoas sumariamente expulsas da Colônia - inclusive o de uma "moça com deficiência mental". Mas, em 1969, no exercício do governador José Sarney, veio uma mudança de política. A Assembleia Legislativa de Maranhão votou uma lei conferindo um salário mínimo mensal a todos os internos que tinham recebido alta, desde que aceitassem sair da Colônia do Bomfim.

A essas alturas, existia um intenso trânsito de facto por cima das fronteiras da Colônia: "Já naquela época, quando dava negativo, podíamos trabalhar [fora]' me garante

\footnotetext{
${ }^{14}$ Tenho nas minhas notas apenas uma menção desse termo: quando uma mulher acusa seu marido de a ter abandonado para ficar com outra mulher "bem piorada".
} 
um senhor. Outro ex-paciente, internado em 1966, me fala que, depois de 19 meses de tratamento, ele começou um vaivém sazonal entre a Colônia e sua cidade a cinco horas de estrada: "tinha que ir botar roça". Também ouvi diversas histórias de crianças "sadias" que, para ficarem perto da mãe ou pai internado, vieram morar com algum parente ou amigo no bairro contíguo à Colônia. E não era inusitado a mãe de uma criança doente procurar moradia na vizinhança da Colônia para poder acompanhar - ainda a certa distância - o tratamento de seu filho. Havia também os cônjuges que, tendo recebido alta, mudavam para o outro lado do portão enquanto esperavam seu marido ou mulher negativar e também ganhar alta. Assim, em muitos casos - talvez a maioria -, "sair" da Colônia significava se mudar apenas algumas quadras, para o lado de lá do portão onde já diversos ex-internos e familiares de internos tinham construído suas barracas.

Os ex-internos, mesmo depois de receber alta e aproveitar a "Lei de Sarney", relutavam em se mudar para longe. Além das importantíssimas relações sociais que tinham travado durante o período de internação - o que dava abertura não só a redes de sociabilidade mas também a possibilidades de emprego -, existia o assunto de medicação. Joana explica como, em 1977, recebendo alta depois de cinco anos na Colônia, "não queria voltar para o interior. Eu estava 'sem defeito', mas ainda tomando remédio". Quantas pessoas falam sobre a dificuldade que tiveram, antes da internação, em conseguir remédio adequado no interior! Em geral, suas moradias eram no seringal, a horas de barco do posto de saúde mais próximo e, quando conseguiam chegar ao posto, nem sempre encontravam o medicamento indicado. Mesmo depois de "curados", os ex-pacientes não só continuavam tomando remédios (alguns, durante décadas), mas podiam sofrer "reações" - isto é, sequelas da doença que se manifestavam na forma de feridas, febre ou outros problemas agudos. Nessas circunstâncias, morar ao lado do hospital onde seguira tratamento durante a internação dava uma segurança que seria difícil encontrar em outros lugares.

Joana tinha outro motivo para não voltar para sua aldeia original - receio da discriminação que sofreria por causa da doença. Lembra que, quando foi diagnosticada com "lepra", ela já era uma mulher casada, com nove filhos. Em razão do medo que os vizinhos tinham do contágio, não só sua casa e todos seus pertences foram incendiados, mas seus filhos foram expulsos da escola pública local. Saindo da Colônia, Joana receava voltar para um lugar onde era conhecida e estigmatizada pela doença. Assim, persuadiu o marido a se mudar do seringal, com os nove filhos, para engrossar as fileiras de Vila Nova, um loteamento "que Sarney deu para nós" a uns 5 km da Colônia.

Evidentemente, nem todos os pacientes da Colônia estavam de acordo quanto às vantagens da lei de 1969. No caso de pessoas como Joana, que queriam voltar a viver junto a suas famílias, a possibilidade de sair era claramente bem-vinda. Mas havia também pessoas 
como Pedro que, depois de cinco anos na Colônia, já tinha esposa e rotina de vida bem consolidada " lá dentro":

Lembro que um belo dia em novembro de 1973, me chamaram para a prefeitura. Mario Ramos (o prefeito de então) me falou: "Você está de alta". Eu pensei "Como? Não pedil" Mas ele insistiu: "Pode ficar até o dia 9 de janeiro. Depois tem que sair. Vai ter que trabalhar e se manter."

Dona Laurinda comenta táticas ainda mais draconianas para persuadir os pacientes a sair:

Aqui estava cheio de gente, tudo cheio de gente. Só saíram porque começaram a derrubar os barracão. Era no tempo de Dr. Vasco (diretor da colônia). Diziam que se ainda tinha gente, iam derrubar em cima deles. Então o pessoal pegava o dinheiro da alta e se mandava.

O benefício tinha a questão territorial como eixo. Ganhava-o quem tinha estado "dentro" da Colônia e estava aceitando sair para "fora". Porém, mais uma vez, na prática, o fator decisivo parecia ter mais a ver com os sinais corporais - os estragos feitos pela doença do que com direitos outorgados pela lei. Os "melhorados" eram os primeiros a acatar a oportunidade de voltar à vida fora da ordem institucional. Os mais sequelados, tais como Seu Vitor e Dona Laurinda - seja porque não quiseram arriscar a vida "fora", seja porque sua presença era mais tolerada pela direção da Colônia - só receberam alta mais de dez anos depois da "lei Sarney", numa época quando a classificação não mais significaria expulsão compulsória da Colônia.

O exato momento da alta tem repercussões também para traçar fronteiras entre diferentes categorias de filhos de ex-internados. Conforme os organizadores do movimento político pleiteando reparação pelos filhos de pacientes compulsoriamente internados ${ }^{15}$ a data de "alta" do pai ou da mãe faz toda a diferença. Crianças nascidas antes entrariam na categoria de "filhos separados"; crianças nascidas depois da alta - isto é, em circunstâncias que permitiam a convivência familiar - não. Dessa maneira, se eventualmente a causa dos "filhos" for vitoriosa, as indenizações vão criar novas demarcações no seio mesmo do grupo de irmãos.

Diante das diversas linhas de demarcação de meu campo - linhas em constante redefinição --, eu me perguntava: Como sei se estou dentro ou fora do campo? Meus diários me lembram que entrei pela primeira vez na Colônia do Bonfim no início de junho de 2015, junto com colegas de INAGEMP ${ }^{16}$ e MORHAN, para apoiar o movimento dos "Filhos". Voltei um ano depois para dar continuação ao trabalho. Mas será que, desde então, consegui "sair" do campo?

\footnotetext{
${ }^{15}$ Existe uma série de projetos de lei tramitando no Congresso Nacional propondo diferentes formas de reparação (apologia, indenização financeira) para pessoas que, quando crianças, tiveram o direito à convivência familiar negado por causa da política nacional de segregação compulsória dos atingidos de hanseníase ( FONSECA; MARICATO, 2013. FONSECA, 2015).
}

${ }^{16}$ Instituto Nacional de Genética Médica Populacional da Universidade Federal do Rio Grande do Sul. 


\section{NÓS-ELES: “PARA A SENHORA, ESSA DOENÇA NÃO EXISTE"}

Durante as Paraolimpíadas de setembro, 2016, recebi um telefonema via WhatsApp de Seu Vitor. Além de botar a fofoca em dia, queria saber se eu estava assistindo aos jogos, pois, "para qualquer um que visse, era uma lição de vida". Seu Vitor é indiscutivelmente o morador "antigo" mais ativo da ex-Colônia hoje. Mão direita de Doutora Ana (a trabalhadora de saúde e diretora do Memorial montado no coração da comunidade), ele dá palestras frequentes sobre a história desse lugar. Além de ser extremamente ativo na vida da pequena paróquia, há muito tempo que é referência na mediação das mais variadas questões entre a administração hospitalar (que ainda tem jurisdição sobre as terras) e os residentes da comunidade. É ele que pleiteia a causa de algum ex-residente que quer voltar para ocupar uma das casas abandonadas. É ele que recebe os funcionários da prefeitura para mostrar a decadência dos prédios e reivindicar investimentos para melhorias. E é ele que inevitavelmente recebe a longa fila de estudantes - de história, de psicologia, das áreas médicas e... da antropologia - que pedem para ele repetir pela enésima vez os pormenores da Colônia de "antigamente".

Um dia, conduzidos em carro por um amigo de Seu Vitor, saímos para um centro comercial fora da zona de conforto da Colônia. Foi então que meu interlocutor desatou a falar sobre as dificuldades da rotina diária de quem não tem dedos funcionais. Como sempre, contava a maioria de suas anedotas em tom de pilhéria, mas em certos momentos sua expressão demonstrava frustração e indignação. Falou da exasperação que sentia diante de uma administração hospitalar que, até hoje, não soube fornecer roupas adequadas às necessidades de pacientes com hanseníase ("não pode ser com botões; tem que ser com aquela fita adesiva..."). Descrevia como ele mesmo enjambrava ganchos na parede do chuveiro para poder agarrar o sabão, como fabricara um instrumento - a partir de um lápis fincado numa pequena borracha - para operar o teclado do computador. Ficou horas rindo do interlocutor ingênuo que, depois de comentar a violência crescente da vizinhança e os perigos que os residentes da ex-Colônia corriam, recomendou que certo ex-interno muito sequelado comprasse um revólver para se defender. "O cara tinha esquecido que, para alguém sem dedos, um revolver é inútil; é impossível puxar o gatilho". E, evidentemente, para me lembrar como ninguém é indefeso... contava a história de como um ex-residente, que tinha sido policial militar antes de adoecer, conseguiu enfrentar o ladrão que arrombou sua casa. Com gestos ilustrativos, descreveu como o ex-policial prensou entre seus dois punhos o revólver e, sem tirá-lo da mão do agressor, o virou contra o peito do próprio ladrão: "Pode atirar. Vai em frente, atire! Ou sai da minha casa!"

Nessas histórias, Seu Vitor ora me posiciona como cúmplice - alguém que ele consegue fazer rir, alguém levado a simpatizar com a condição de pessoas como ele que 
viveram longos anos de uma experiência singular. Ora, de forma sutil, me coloca como "outro" - alguém como os administradores do hospital que enviam roupas com botões, alguém que esquece constantemente o que é viver num corpo que difere tanto do padrão normal. Dependendo de sua disposição, pode me tratar como uma interlocutora de confiança, me presenteando com incontáveis detalhes históricos, ou como uma tonta para quem pode contar histórias fantasiosas (sem piscar o olho, pode nos dizer, por exemplo, que perdeu os dedos olhando jogo de futebol: de tão nervoso que ficava, roía as unhas até não sobrar mais nada dos dedos). De fato, vejo que meu "lugar" nessa interlocução não é estável; é constantemente redefinido por nossas interações, redistribuído entre sítios ora mais próximos, ora mais afastados. Ao mesmo tempo que existe entre nós um sentimento palpável de amizade, ao mesmo tempo que há possibilidades de diversas colaborações práticas - inclusive alianças políticas em prol da causa dos ex-internos -, tenho a impressão de que nunca escaparei de ser, para ele e para os seus vizinhos, um "outro". Como disse Dona Ana (internada com 12 anos de idade na colônia), quando confessei minha confusão quanto aos tipos de hanseníase: "É que, para a senhora, essa doença não existe".

A frase não veio em tom de acusação, e, sim, de afirmação mais do que óbvia. Não sou uma "atingida de hanseníase". Não sei o que é sentir as angústias do diagnóstico, as náuseas do tratamento, a rejeição social, ou simplesmente o cansaço de uma doença crônica que parece não ter fim. Não faço parte daquela categoria que arrola trinta mil novos brasileiros todo ano. Nunca senti "na pele" o que é sofrer dessa doença. Tampouco fui um bebê separado e enviado ao orfanato por medo do contágio, ou rechaçado por vizinhos por causa do pai ou mãe infectados. Não tive que lidar com a rotina diária de cuidar de alguém sob tratamento ou com sequelas. Não tenho que viver dentro dos estreitos limites de uma precariedade econômica legada pela doença dos meus pais. A hanseníase, até muito pouco tempo atrás, era para mim um país exótico, distante e curioso. Dona Ana, de forma amigável, me lembrava minhas limitações ao mesmo tempo que - ao longo de duas horas de conversa - indicava possíveis pistas para eu tentar superá-las.

O telefonema de Seu Vitor tinha me mostrado que o "campo" não ficava restrito a "lá", naquela "aldeia" a oito horas de voo da minha casa. Estava também "aqui" (em Porto Alegre), me acompanhando nas rotinas do dia-a-dia, entrelaçado com minha própria vida familiar. Por outro lado, os sinais sutis emitidos pelos meus interlocutores me lembravam que eu jamais chegaria completamente "dentro" da comunidade. Posso me "posicionar" nessa relação, mas, ao mesmo tempo, sou posicionada e, no processo, muita coisa extrapola empatia e engajamento político. Paradoxalmente, cheguei à conclusão de que, em certas situações, para superar as barreiras que nos afastam, temos que reconhecer certos elementos inexoráveis da diferença. 


\title{
O TRABALHO ÁRDUO DO POSICIONAMENTO
}

Mas, não posso terminar aqui. Gupta e Ferguson (1997), no artigo que inspirou minha reflexão, não fizeram toda uma retomada da tradição etnográfica para simplesmente reiterar - em nova roupagem - truísmos humanistas. O "posicionamento" implica em entrar num circuito de interlocutores cujos desafios não só extrapolam as orientações estabelecidas pelos comitês institucionais de ética, também vão além das (já) tradicionais respostas metodológicas de intersubjetividade e autorreflexão. Gupta e Ferguson (1997), ao se referirem a uma forma particular de engajamento político engendrado pela experiência etnográfica, procuram um caminho para enfrentar esses desafios:

\begin{abstract}
"Ao invés de considerar os antropólogos detentores de conhecimentos e insights privilegiados que podem ser compartilhados ou acionados por eles em prol de diversas 'pessoas comuns', nossa abordagem enfatiza que o conhecimento antropológico coexiste com outras formas de conhecimento. A tarefa política, no nosso entender, não é 'compartilhar' conhecimento com quem não o possui, mas sim forjar laços entre os diversos possíveis saberes de diferentes sítios e esboçar linhas possíveis de aliança e um propósito comum" (GUPTA; FERGUSON, 1997, p. 39).
\end{abstract}

A primeira parte dessa proposta - que os conhecimentos do antropólogo não são privilegiados - é bastante clara para mim. Tenho a sensação de que há pouca informação realmente original nos meus textos. A grande maioria dos meus insights etnográficos são nada mais do que uma reedição do que aprendi com meus interlocutores no campo. Mas essa reedição, formulada para contar certa história, implica numa série de opções não só éticas, mas também políticas, que são responsabilidade minha - o que nos leva para a segunda parte da proposta de Gupta e Ferguson (1997): esboçar linhas possíveis de aliança.

Essa sugestão é convincente no papel. Mas, como operacionalizá-la no meu caso específico? Onde começar? Acontece que as pessoas que gravitam em torno das antigas Colônias são extremamente variadas. Minha entrada no tema foi através do movimento social, MORHAN, pelo o qual guardo enorme admiração. Fundado por ex-pacientes de Colônias espalhadas pelo país - líderes carismáticos, intelectuais orgânicos - o movimento segue pleiteando há mais de três décadas reparação por direitos violados, além de serviços abrangentes de reabilitação e medidas eficazes de prevenção e tratamento da doença em escala nacional. Mas nem todos meus interlocutores se entusiasmam da mesma forma com esse movimento. Alguns deles dedicam suas lealdades antes de tudo à Igreja católica, trabalhando junto com o padre local para reunir e ajudar membros da comunidade. Vinda deles, a demanda mais imediata pode ser a reforma da igreja paroquial, a restauração de estátuas devocionais ou a doação de cestas básicas no âmbito de uma das muitas iniciativas da igreja.

Outros dos meus interlocutores procuram na aliança com pesquisadores "de fora" ajuda no fortalecimento de uma memória coletiva. Sem dúvida, o Memorial do Bonfim - 
ainda nas suas modestas proporções - é um local que concentra energias políticas. Graças à dedicação de certa terapeuta ocupacional, o lugar serve como centro comunitário canalizando as reivindicações de vizinhos por melhorias prediais e de infraestrutura, oferecendo assessoria jurídica e assistencial e acolhendo, além de autoridades visitantes, pesquisadores de todas as áreas. Ainda outros de meus interlocutores - certos profissionais de saúde, por exemplo - abraçam como causa política principal o tratamento adequado dos atingidos de hanseníase e campanhas para a deteç̧ão precoce da doença. Finalmente, conhecemos ainda outras pessoas que não se identificam com nenhum pleito coletivo em particular, procurando apenas garantir o bem-estar próprio e de seus familiares frente às precaríssimas condições de vida. Diante da heterogeneidade de interesses e engajamentos, a questão é: como definir um "propósito comum"?

No âmbito dessa discussão, o título deste artigo assume novos contornos. Perguntar "Lá onde, cara pálida?" não mais se refere apenas a fronteiras apagadas entre um dentro e um fora, mas à própria naturalidade com a qual falamos de "posicionamento". A experiência da pesquisa de campo afeta profundamente a maneira como forjamos nosso "lugar". Mas as alianças que acabamos priorizando têm também a ver com nossas convicções pessoais (éticas e estéticas), entrelaçadas a experiências de vida, que vão além do "campo".

\section{UMA ETNOGRAFIA RESPONSIVA E PROVOCADORA}

Afinal, o "propósito comum" evocado por Gupta e Ferguson talvez não seja o termo mais adequado. Poderia carregar a conotação de divergências reconciliadas e diferenças anuladas - algo que Annelise Riles (2008), no seu esboço de uma "etnografia como modalidade de resposta", rechaça. Рara esta autora, são justamente as diferenças que dão aos etnógrafos a possibilidade de ser "responsivos". Ser "responsivo" teria vizinhança com noções caras a discussões recentes sobre a experiência do etnógrafo no campo. Penso, em particular, nas noções de "ser afetado" e "devir" citados por Goldman para evocar "o movimento através do qual um sujeito sai de sua própria condição por meio de uma relação de afetos que consegue estabelecer com uma condição outra" (GOLDMAN, 2003, p. 464). Contudo, eu gostaria de sublinhar ainda outros elementos inspirados nesse meu último campo.

Em primeiro lugar, essa "condição outra" não implica em categorias fixas. Como meus interlocutores em São Luís me mostraram, o dentro-e-fora de qualquer categoria não é nada evidente. É fruto de uma dinâmica em que os diferentes elementos - tanto o corpo e relações pessoais, quanto as instituições legais e médicas - estão em fluxo contínuo. Nesse cenário, vale lembrar o conselho proferido por Lila Abu-Lughod para evitar o olhar orientalista (o mundo dividido entre "nós" e "eles") da antropologia clássica. A resposta do 
etnógrafo não seria apagar as diferenças, e, sim, multiplica-las, reconhecendo as vias complexas e entrecruzamentos entre elas (ABU-LUGHOD, 1996, p. 146).

Essa multiplicação nos leva a pensar que nossos encontros etnográficos, por intensos e duradouros que sejam, não devem ser reduzidos a uma relação a dois. Para esse segundo ponto de meu argumento, apelo para a noção latouriana de ator: aquilo "que é levado a agir por muitos outros atores" (LATOUR, 2005, p. 45). A relação pesquisador-pesquisado se insere numa rede de muitas entidades interconectadas onde é quase impossível dizer exatamente em que ponto a ação se origina ${ }^{17}$. Na descrição que desenvolvo neste artigo, privilegio certas entidades -- os micróbios, os corpos, as leis --, cada uma já tendo sofrido interferências antes de exercer uma influência sobre meu interlocutor e a relação deste comigo. Mas essas entidades poderiam ser desdobradas em centenas mais. Por outro lado, não seria difícil traçar uma rede semelhante ao redor do pesquisador. Aqui, limito-me a ilustrar essa rede apontando para uma conexão entre meu network e o de Seu Vitor -- justamente para demonstrar a maneira em que "a ação transborda" (action is overtaken) além da intencionalidade de um ator.

Antes de ir ao Maranhão pela segunda vez, fiz questão de consultar o trabalho de antropólogos que tinham estudado a Colônia do Bonfim - autores que estavam conectados igualmente a mim (como colegas acadêmicos) e aos meus eventuais interlocutores de campo (como entrevistadores e conhecidos pessoais). Em particular, me interessavam duas dissertações de Antropologia, cheias de anedotas e memórias dos moradores da Colônia (CÂMERA, 2009; NASCIMENTO, 2010). Nesses textos, os nomes dos personagens tinham sido trocados para garantir o anonimato dos participantes, e - em todo caso - meu interesse estava mais nos detalhes históricos e nos insights analíticos do que na identificação de pessoas em carne e osso. No entanto, ao escutar Seu Vitor acrescentando mais e mais detalhes à sua anedota de como perdeu os dedos da mão - como ele insistiu para que certa dentista arrancasse seus dentes de frente, apesar deles estarem em perfeito estado, justamente para ele não roer mais as unhas, devorando também os dedos - me deu um estalo. Lembrei de um personagem descrito por Câmera (2009), um homem extrovertido que gostava de contar, risonho e com orgulho, como inventava cada história para explicar suas mãos deformadas pela hanseníase para pessoas ingênuas da cidade. Só podia ser Seu Vitor.

Câmera (2009) via essas anedotas como estratégia para evitar o olhar preconceituoso de pessoas estranhas à Colônia. No meu caso, não havia questão de disfarçar o passado de

\footnotetext{
${ }^{17}$ Criticando a ideia de interação face-a-face, Latour insiste que "Na maioria de situações, as ações já sofreram interferência por entidades heterogêneas que não possuem a mesma presença local, que não vêm do mesmo tempo, que não são simultaneamente visíveis e que não exercem [sobre as ações] o mesmo peso" (2005, p. 202).
} 
hanseníase. Seu Vitor parecia estar contando a história pelo prazer de exercer sua criatividade, combinando charme e sedução para produzir um efeito de fascínio entre seus parceiros em diálogo. Muitas vezes, nas minhas conversas com interlocutores de campo, uma combinação de interesse e perplexidade me deixam sem comentário. Mas, nessa ocasião, não pude me conter: "Está mexendo comigo, né Seu Vitor?" Sem perder o ritmo da sua narrativa, ele soltou um riso quase imperceptível e, piscando para mim com os cantos da boca, mudou para outro assunto. Seguramente, a intromissão de Câmera na nossa conversa tinha facilitado minha entrada em certo circuito de entendidos, cambiando a relação pesquisado/pesquisador.

Conforme Riles (2008), apreciar as semelhanças e diferenças (entre pessoas, entre sítios, entre textos) seria um procedimento constitutivo da etnografia. O texto etnográfico é um artefato que materializa a "resposta" do pesquisador à experiência de campo. O pesquisador, como parte de uma comunidade acadêmica, acaba sendo "responsivo" aos artefatos elaborados por seus colegas. A etnografia, nesse sentido, seria sempre uma espécie de experiência colaborativa - envolvendo não só os interlocutores de campo, mas também colegas acadêmicos (e outros). Seria nas "ressonâncias imprevisíveis" que emergem dos artefatos/textos/sujeitos e ideias justapostos - e não no achatamento da diferença entre eles por alguma padronização estética, teórica ou política - que o etnógrafo acharia seu norte.

Esse movimento "colaborativo" serve para introduzir meu terceiro (e último) ponto. Já aceitamos como premissa que os insights antropológicos não são privilegiados, que existem em diálogo com outras formas de conhecimento. Sugiro agora que esse diálogo deve ser orientado para um aprofundamento de reflexão - deve ser provocativo. Certamente, a ambição de "avançar" nos debates acadêmicos e políticos faz parte de nossos textos escritos. A "desconstrução" (do Estado, da família, de gênero, etc.) já virou o feijãocom-arroz de nosso ofício. Porém, muitas vezes, nossas provocações se restringem ao âmbito relativamente seguro do debate acadêmico. Gostaria de extrair essa atitude questionadora da quarentena de nossos textos escritos e pensá-la em termos dos diferentes diálogos que travamos (e esperamos travar) ao longo do empreendimento etnográfico.

Existem interessantíssimas discussões sobre o "retorno" de pesquisa, quando o estudante enfrenta o desafio de discutir as conclusões de suas análises com membros da comunidade pesquisada (SCHUCH, 2013; FASSIN, 2013). Mas estou pensando também no início e meio da pesquisa - na maneira como levamos as conversas durante o campo. Certamente, diante de situações (sempre) novas, cabe ao pesquisador uma boa dose de tímida cautela; deve pensar trinta vezes antes de proferir conselhos ou emitir opiniões precipitadas. Mas, quantas vezes senti o convite implícito de meu interlocutor a ser tratado não como espécimen sob exame laboratorial e, sim, como verdadeiro parceiro em diálogo. 
Queria que eu também aceitasse me expor, vocalizando minhas próprias atitudes. Atentar para a "voz do nativo" não significa isolá-la de qualquer intervenção nossa. Incorporar os diferentes atores na rede de um parlamento democrático, rejeitando a fria observação típica da "história natural" colonialista, significa reconhecer o desafio e aceitar o risco de trocas provocadoras. Saber como assumir sua ignorância, como discordar, como chamar atenção para perspectivas diferentes - num tom e estilo que não reforcem velhas hierarquias de autoridade, nem criem rixas ou "campos inimigos" - é, para o pesquisador, um elemento fundamental de sua (nunca acabada) aprendizagem.

Talvez, antes de falar em alcançar um "propósito comum", seja mais realista almejar, tal como Latour (2005) sugere, "viver num mundo comum". Conforme a "epistemologia política" que esse autor busca promover, não seria suficiente o pesquisador tornar visível o grande leque de maneiras diferentes de viver no mundo. Restaria ainda a tarefa de "reagregar o social", isto é, ajudar na consolidação de um fórum desenhado em termos de alguma maneira aceitáveis pelas pessoas que nele coabitam (LATOUR, 2005, p. 256). No "livable world" almejado tanto pela etnografia responsiva quanto pela epistemologia política, as investidas críticas do pesquisador seriam formuladas de maneira a encorajar o diálogo. Numa "ética de cuidado" (BELLACASA, 2011), haveria entre os atores (e perspectivas divergentes) um respeito que modera a suspeita, uma escuta que previne julgamentos precipitados. Decorre daí um posicionamento do pesquisador que é ao mesmo tempo provocador e cuidadoso. Existe aqui algo da perspectiva humanista que evoquei acima, é verdade. Contudo, o destaque no caráter inescapavelmente político da produção acadêmica (e etnográfica) faz uma diferença, assim como a assunção pelo pesquisador da responsabilidade pelos efeitos do que ele produz.

Reagregar o social implicaria em mediações das mais variadas (a restauração da estátua do santo, a formulação de um projeto de lei, a organização de um acervo memorial, a divulgação de uma campanha de saúde pública, ...), sem descartar nada de antemão. Mas, para muitos pesquisadores, sua contribuição principal reside na particular maneira em que narra o mundo -- relatos tênues, sempre provisórios, que, na maioria das vezes, são inscritos e comunicados por mediação do texto escrito (LATOUR, 2005, p. 256). Hoje em dia, esses textos -- tais como as tecnologias médicas, as lesões corporais e leis discutidas antes -também servem como conectores entre um "dentro" e "fora" do campo, ajudando a redesenhar fronteiras e pontes entre quaisquer "nós" e "eles".

Em suma, desde a época dos nossos pais fundadores, a certeza quanto às distâncias que separam pesquisador de pesquisados evaporou. Os aviões e a internet assim como a bolsa de ações e as corporações transglobais provocaram um redimensionamento não só da distância física, mas também da noção de distanciamento analítico. O "eu estive lá" do antropólogo não se remete mais ao pesquisador observando algum fenômeno natural 
"exterior" a ele. Nessa discussão, não há como isolar o etnógrafo de suas práticas de campo e do seu texto. Os analistas dos Estudos de Ciência e Tecnologia nos ensinam a desconfiar de fronteiras fixas, propondo, ao invés, pensar nos territórios e objetos como fluídos, fogosos, ou "dobrados", onde o "dentro" e "fora" é longe de ser evidente (M'CHAREK, 2014; BUMACHAR, 2016). São fenômenos (humanos e não-humanos), cada um com sua própria historicidade, que interagem para compor novas situações. Cada novo cenário envolve novas práticas que operam um rearranjo não-linear do tempo e espaço, obrigando igualmente à renegociação coletiva de compromissos políticos e éticos. Levado a sério não só pelo pesquisador, mas também pelos diferentes interlocutores do campo, o "eu estive lá" implica necessariamente em um emaranhado de relações cujas implicações permanecem imprevistas e cujas possibilidades continuam (felizmente) a nos desafiar.

\section{REFERÊNCIAS}

ABU-LUGHOD, Lila. "Writing against culture". In: FOX, R. (Org). Recapturing anthropology: working in the present. Santa Fe, New Mexico: School of American Research Press, 1996. p. 137-162.

BELLACASA, Maria Puig. Matters of care in technoscience: Assembling neglected things. Social studies of science., vol. 41, n. 1, p. 85-106, 2011.

BELTRÃO, Jane Felipe; CAROSO, Carlos. "Patrimônio, linguagens e memória social: problemas, estudos e visões no campo da antropologia". In: LIMA FILHO, M. et al (0rg.). Antropologia e patrimônio cultural: diálogos e Desafios Contemporâneos. Blumenau: Nova Letra, 2007. p. 45-56.

BUMACHAR, Bruna. Nem dentro, nem fora: a experiência prisional de estrangeiras em São Paulo. Tese de doutorado, Universidade de Campinas, 2016.

BRASIL. Lei Federal 11.520 de 2007. Disponível em: http://www.planalto.gov.br/ccivil 03/ ato20072010/2007/lei//11520.htm. Acesso em: janeiro de 2017.

CÂMARA, Cidinalva Silva. 0 começo e o fim do mundo: Estigmatização e exclusão social de internos da colônia do Bonfim. Dissertação do PPG em Ciências Sociais, UFMA, 2009.

CARDOSO, Marina. 2013. "Etnografia entre "éticas": ética e pesquisa com populações indígenas". In: SARTI, Cynthia e DUARTE, Luiz Fernando (0rg.). Antropologia e ética: desafios para a regulamentação. Brasilia: ABA, 2013. p. 131-171.

CURI, Luciano Marcos. Excluir, isolar e conviver: um estudo sobre a lepra e a hanseníase no Brasil. Tese de Doutorado, PPG em História, Universidade Federal de Minas Gerais, 2010.

FASSIN, Didier. "Why ethnography matters: Anthropology and its publics". Cultural Anthropology, vol. 28, n. 4, p. 621-646, 2013. 
FONSECA, Claudia. Time, DNA and documents in family reckonings. Vibrant, Virtual Brazilian Anthropology, v.12, n.1, p. 75-108, 2015.

FONSECA, Claudia; MARICATO, Glaucia. "Criando comunidade: emoção, reconhecimento e depoimentos de sofrimento". Interseções: Revista de Estudos Interdisciplinares, v. 15, n. 2, p. 252-274, 2013.

FOUCAULT, Michel. Vigiar E Punir: Nascimento Da PrisaDo. Petropolis: Vozes, 2011

GEERTZ, Clifford. "Descrição densa: por uma teoria interpretativa da cultura". In Interpretação das Culturas. In: GEERTZ, C. A interpretação das culturas. Rio de Janeiro: Zahar Editores, 1989 [1973]. p. 321.

GOFFMAN, Erving. Stigma: Notes on the Management of Spoiled Identity. Englewood Cliffs, Nova Jersey: Prentice-Hall, 1963.

. Manicômios, Prisoワes E Conventos. SaПo Paulo: Perspectiva, 2007

GOLDMAN, Marcio. "Os tambores dos mortos e os tambores dos vivos. Etnografia, antropologia e política em Ilhéus, Bahia”. Revista de Antropologia, vol. 46, n. 2, p. 423-444, 2003.

GUPTA, Akhil; FERGUSON, James. 'The field' as site, method, and location in anthropology". In: GUPTA, A.; FERGUSON, J.(Org.). Anthropological locations: Boundaries and grounds of a field science. Berkley: University of California Press, 1997.p. 1-46.

HARAWAY, Donna. 1995 [1988]. "Saberes localizados: a questao da ciencia para o feminismo e 0 privilégio da perspectiva parcial". Cadernos Pagu, n. 5, p. 7-42, 2009.

KNAUTH, Daniela Riva; MEINERZ, Nádia Elisa. "Reflexões acerca da devolução dos dados na pesquisa antropológica sobre saúde”. Ciência \& Saúde Coletiva, vol. 20, n. 9, p. 2659-2666, 2015.

LATOUR, Bruno. Reassembling the social: An introduction to actor-network-theory. Oxford: Oxford University Press, 2005.

MAGNANI, José Guilherme Cantor. Da periferia ao centro: trajetórias de pesquisa em Antropologia Urbana. São Paulo: Editora Terceiro Nome, 2012.

MARICATO, Glaucia. "Ordenando sujeitos e constituindo fatos: histórias performadas no pleito por direitos". In MACHADO, H.; FONSECA, C. (Org.). Ciência, identificação e tecnologias de governo. Porto Alegre: Editora da UFRGS/CEGOV, 2015. p. 96-120.

M'CHAREK, Amade. "Race, time and folded objects: the HeLa error". Theory, Culture and Society, v. 31, ก. 6, p. 29-56, 2014.

MENDONÇA, Ricardo. Reconhecimento e deliberação: as lutas das pessoas atingidas pela hanseníase em diferentes âmbitos interacionais. Tese de Doutorado em Comunicação Social - UFMG, Belo Horizonte, 2009.

NASCIMENTO, Jacklady Dutra. A perspectiva dos adoescidos: um olhar antropológico para compreender a hanseníase. Dissertação do PPG em Ciências Sociais, UFMa, 2010. 
RILES, Anelise. "In response". In: RILES, A. (Org.). Documents: Artifacts of modern knowledge. Ann Arbor: University of Michigan Press, 2008. p. 1-25.

SCHUCH, Patrice. 2013. "A vida social ativa da ética na Antropologia (e algumas notas do "campo" рага o debate)". In: SARTI, C.; DUARTE, LFD (Org.). Antropologia e ética: desafios para a regulamentação. Brasilia: $A B A$, 2013. p. 31-85.

SERRES. Juliane. Memórias do isolamento: Trajetórias marcadas pela experiência de vida no hospital Hospital Colônia Itapuã. Tese de Doutorado em Estudos Históricos Latino Americanos - UNISINOS, São Leopoldo, 2009.

VALLE, Carlos Guilherme. "Identidades, doença e organização social: um estudo das 'pessoas vivendo com HIV e AIDS". Horizontes Antropológicos, v. 8, n. 17, p. 179-210, 2002. 